\title{
المعالجة القانونية للمعاملة السيئة للعامل
}

\section{Doi: 10.23918/ilic2021.19}

\section{م. د. د. نورس رشيد طه النه كلية الحقوق / جامعة النهرين رئ nawras.rasheed@gmail.com

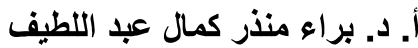 كلية الحقوق / جامعة تكريت Braa-munther@yahoo.com} \section{المقدمة}

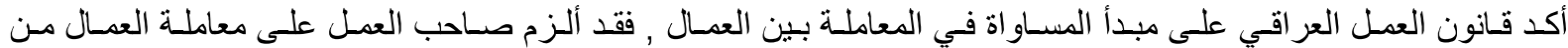

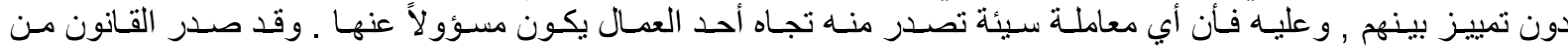

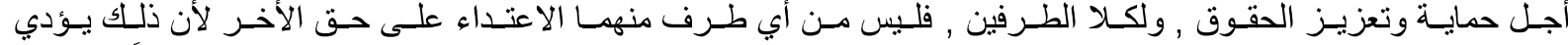

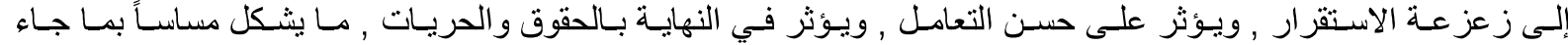

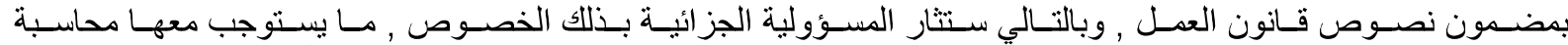

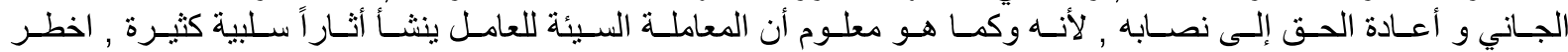

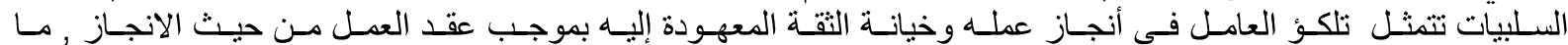

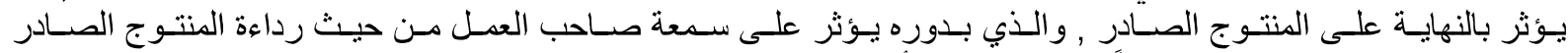

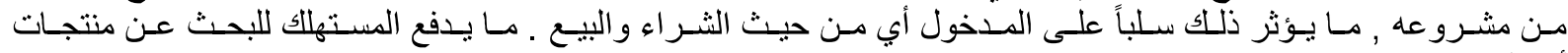

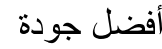

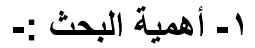

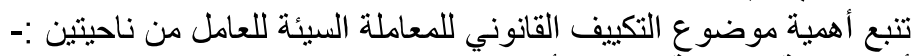

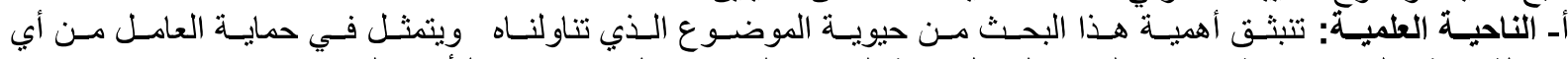

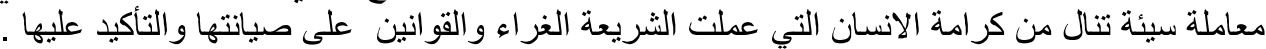

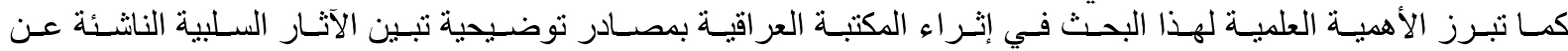

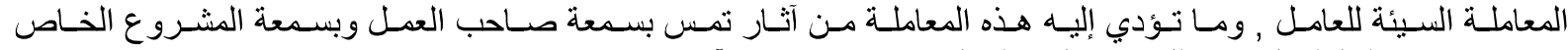

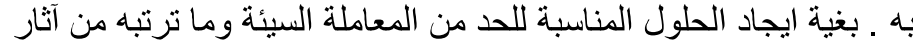

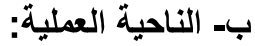

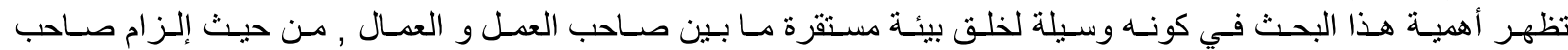

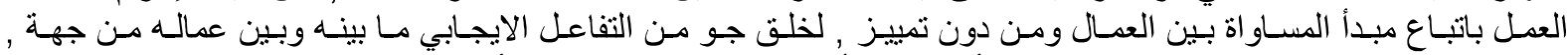

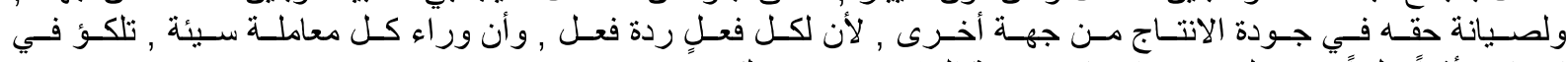

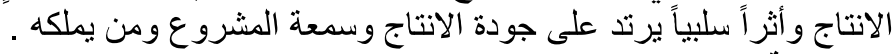

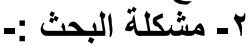

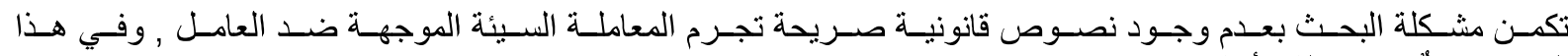

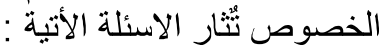

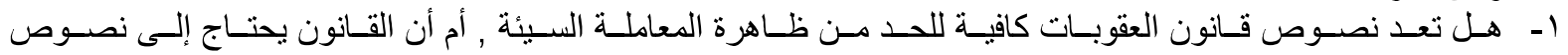

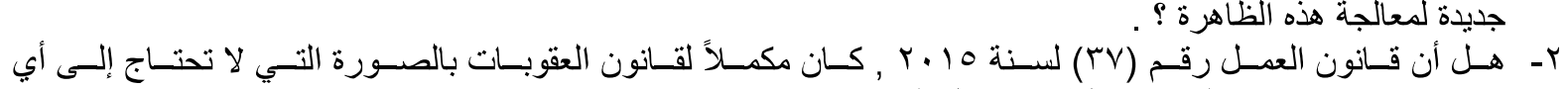
تدخلات تشريعية جديدة لمواجهة الظاهرة محل البحث .

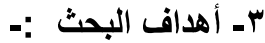

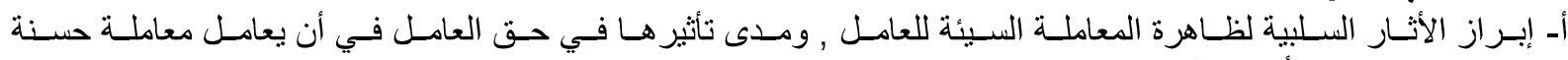

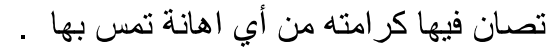

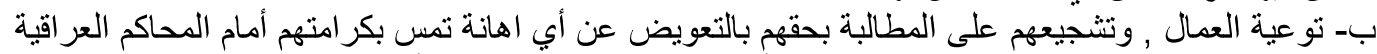

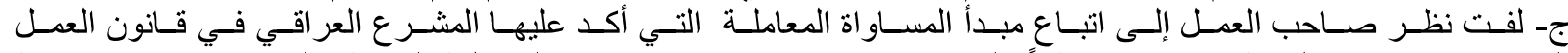

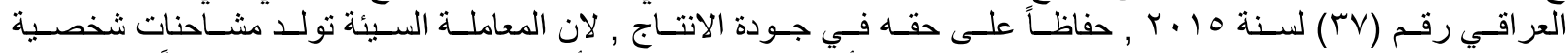

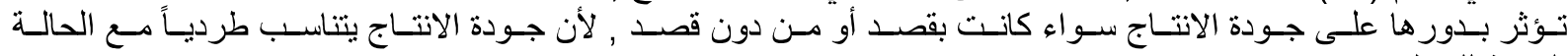

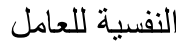

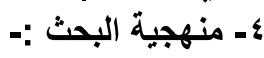
ان المنهج المتبع هو المنهج التحليلي لنصوص القو انين العر اقية النافذة , المتعلقة بموضوع البحث .

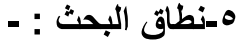

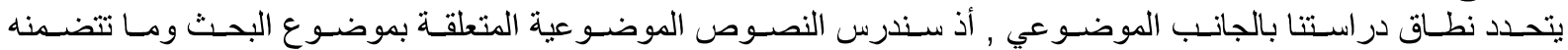

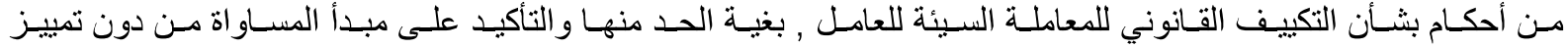

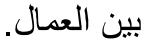


ד- خطة البحث:-

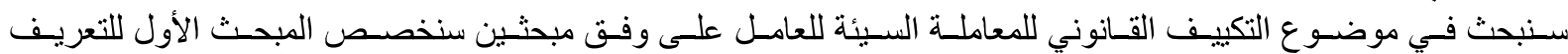

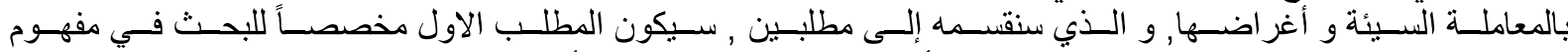

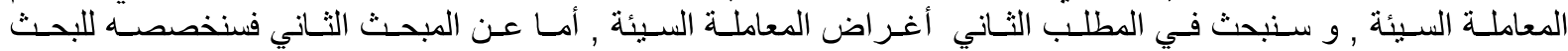

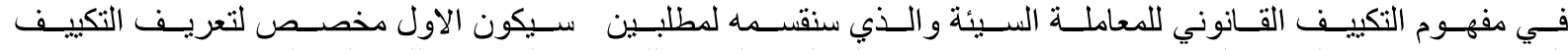

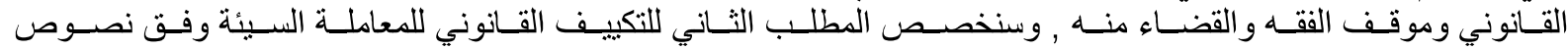

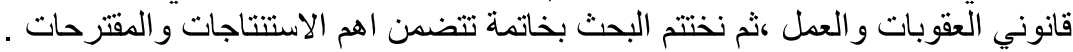

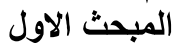

التعريف بالمعاملة السيئة وأغراضه الفها

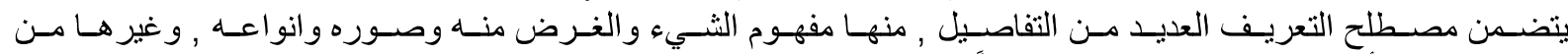

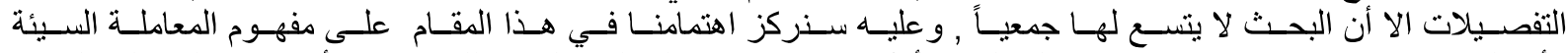

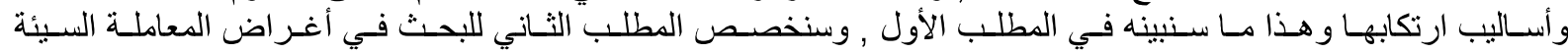

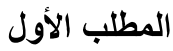

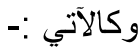

\section{مفهوم المعاملة السيئة و أساليب ارتكابها العابها}

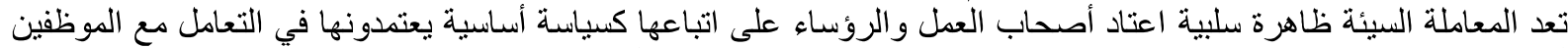

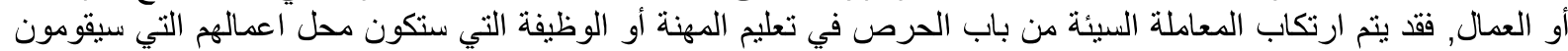

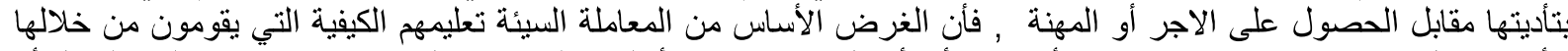

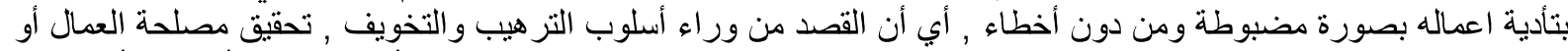

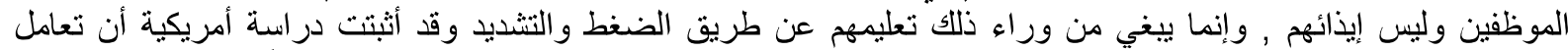

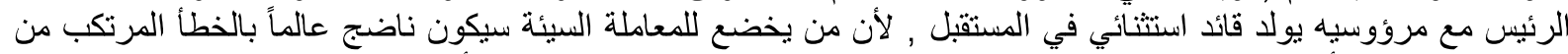

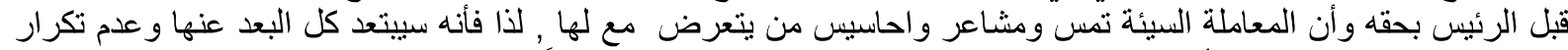

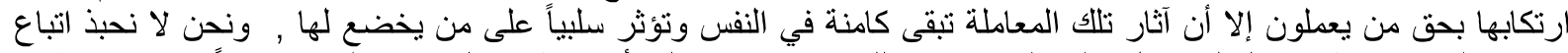

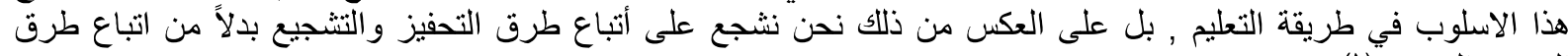

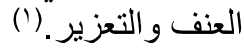

وقد تستخدم المعاملة السيئة من باب الاستهجان والتنمر والانتقاص من العمال , بغية التأثير على نفسيتهم وتشويش أفكارهم ,

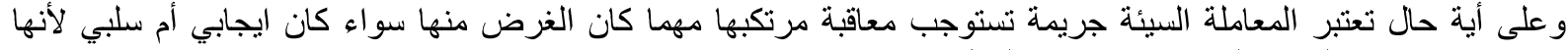

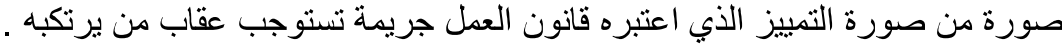

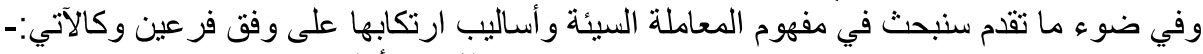

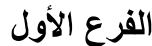

\section{مفهوم المعاملة السيئة}

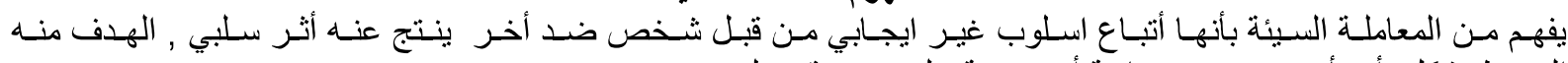

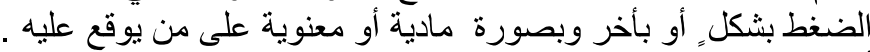

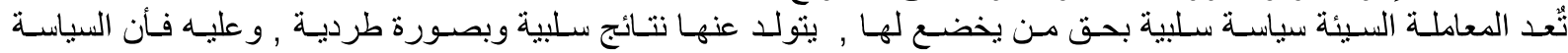

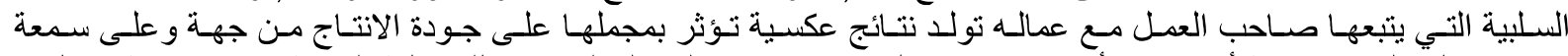

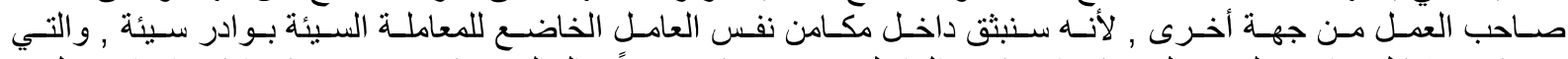

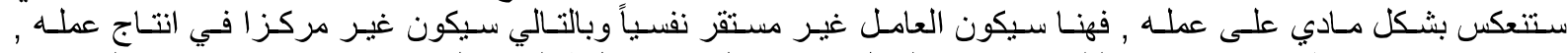

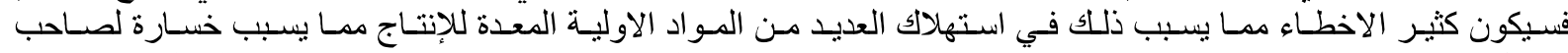

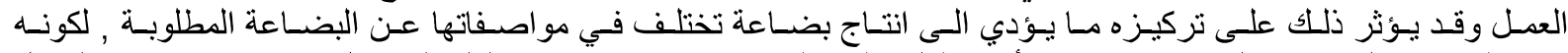

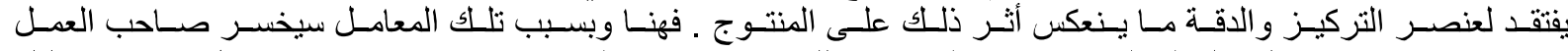

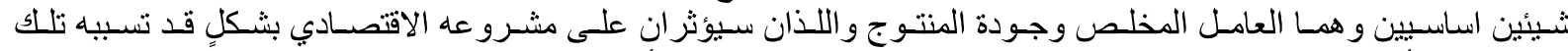

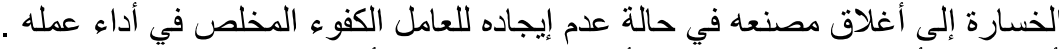

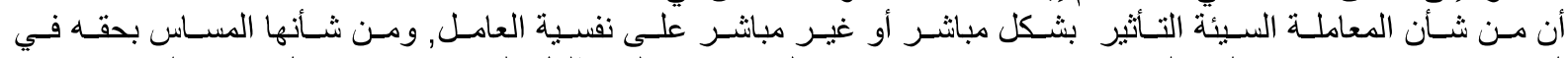

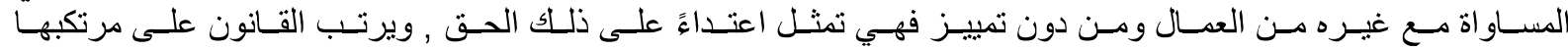

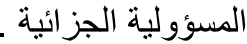

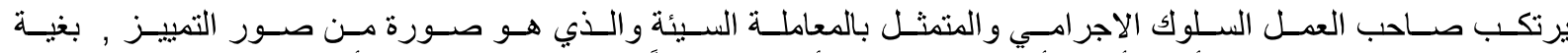

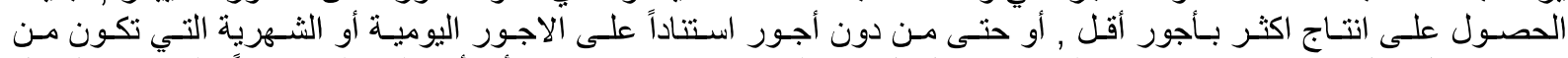

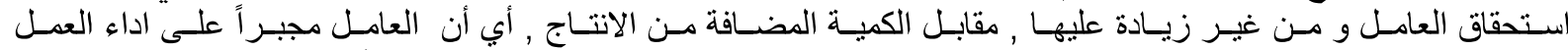

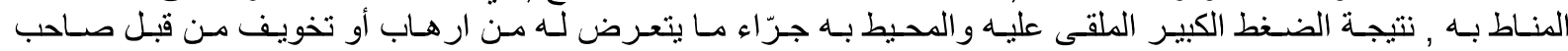

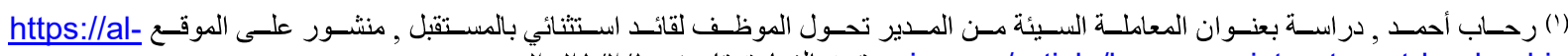
a ain.com/article/bosses-mistreatment-leadership 


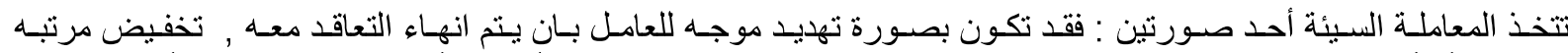

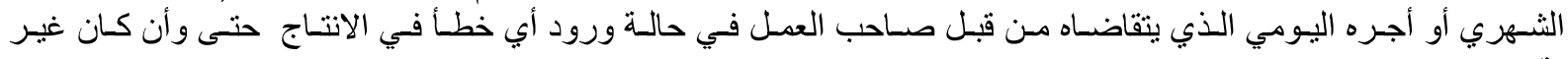
مقصود . مقدي

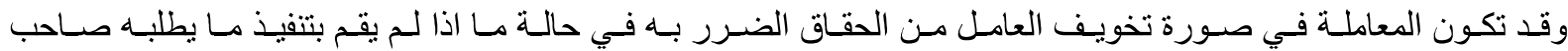

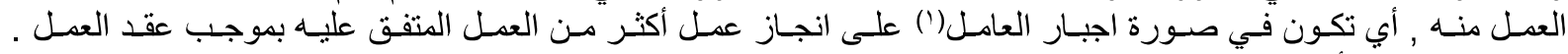

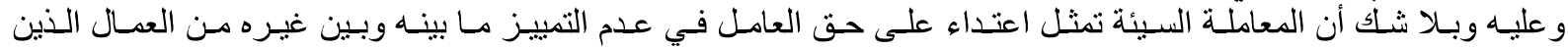

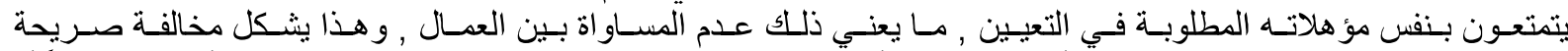

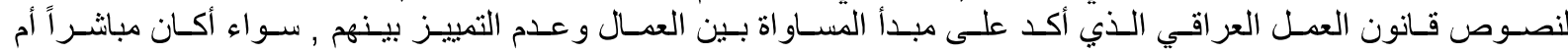

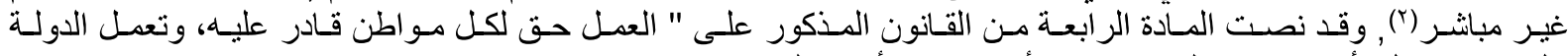

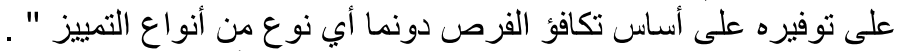

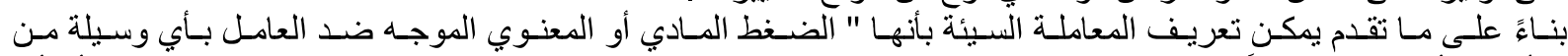

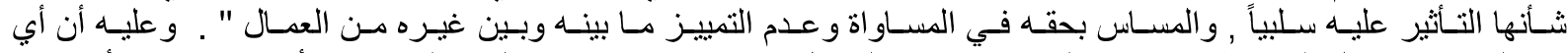

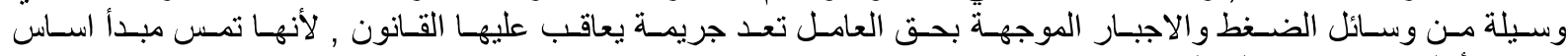
و هو مبدأ المساو اة ما بين العمال

\section{أساليب ارتكاب المعاملة السيئة الثَّي}

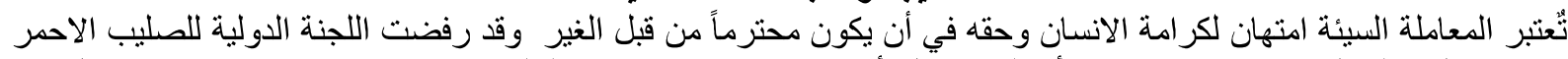

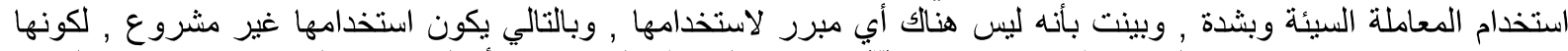

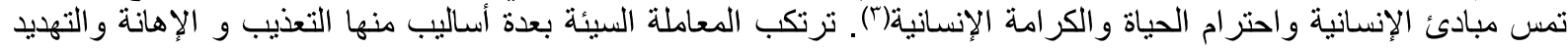

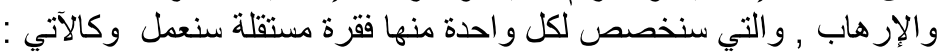

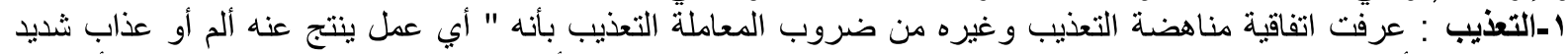

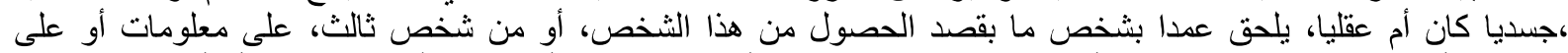

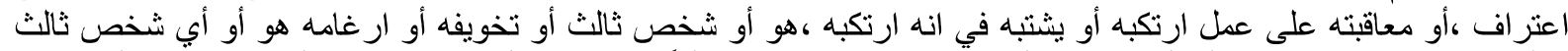

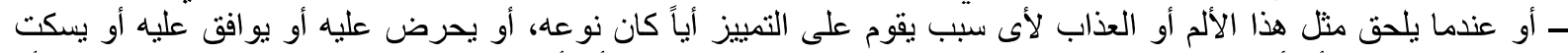

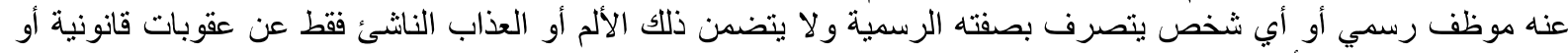

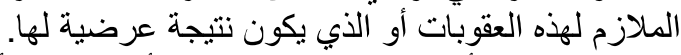

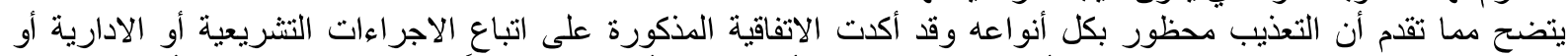

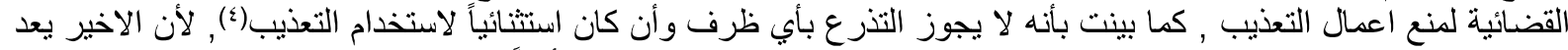

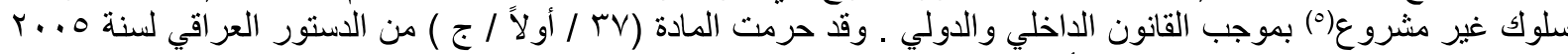

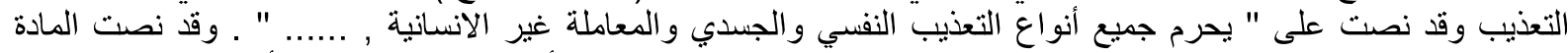

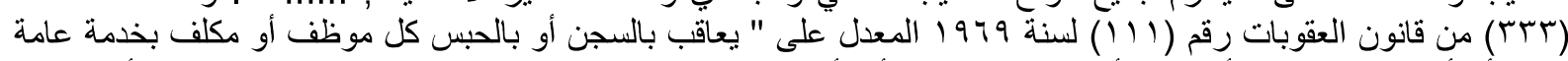

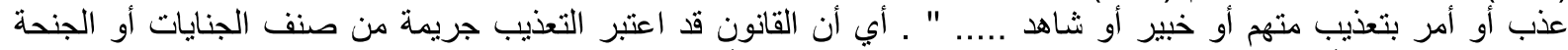

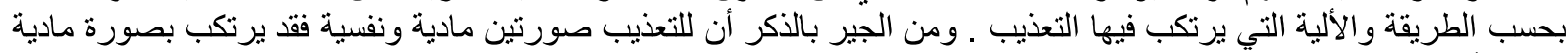

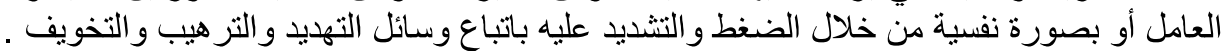

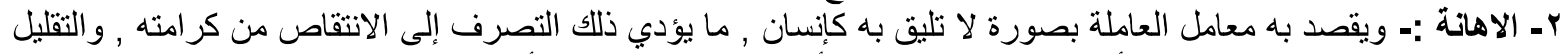

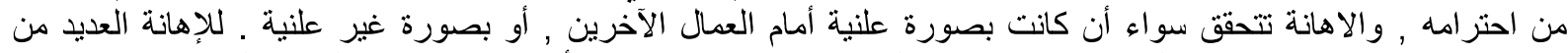

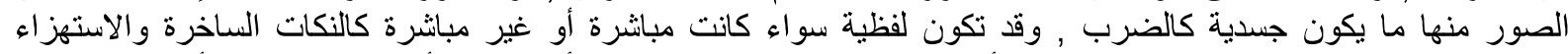

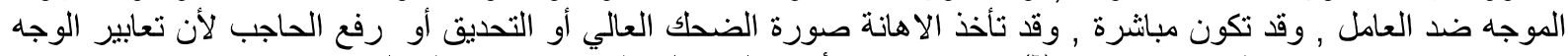

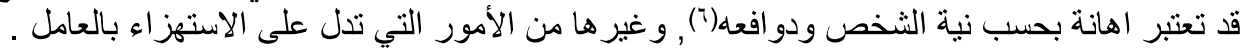

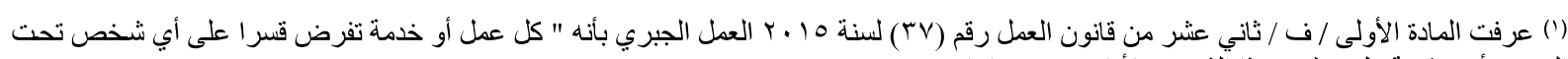

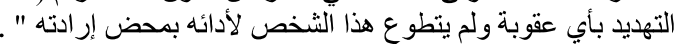

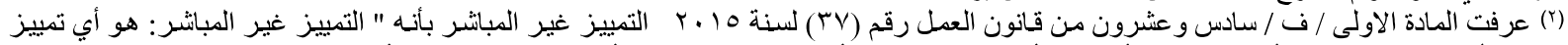

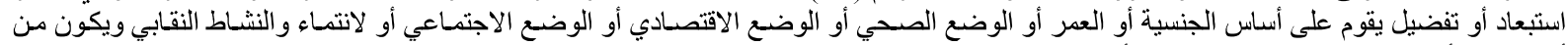

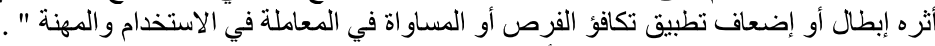

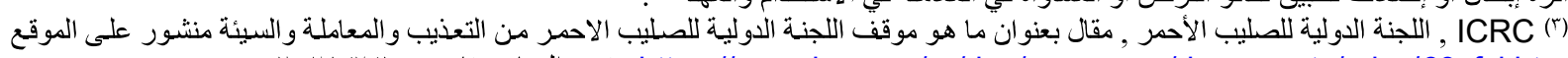

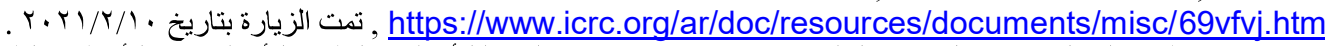

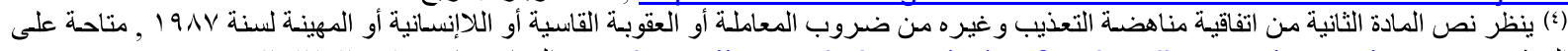

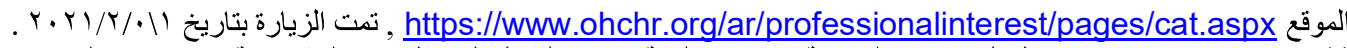

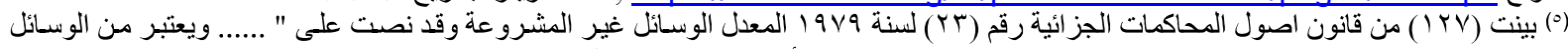

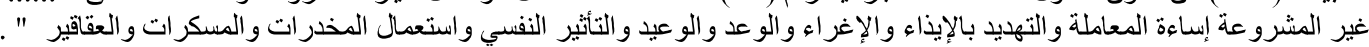

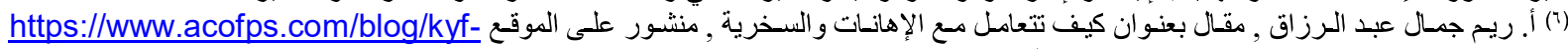

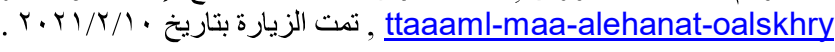




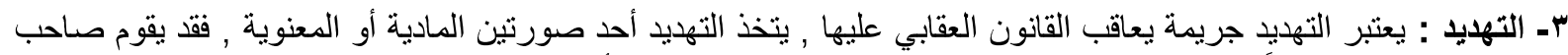

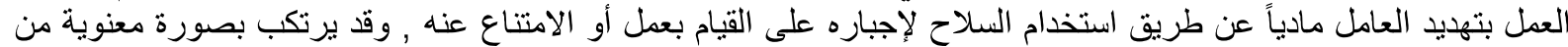

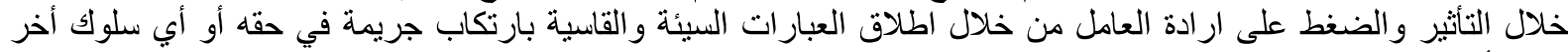

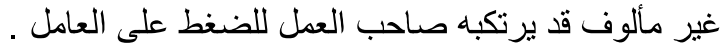

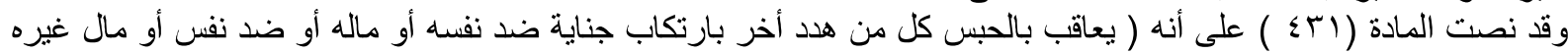

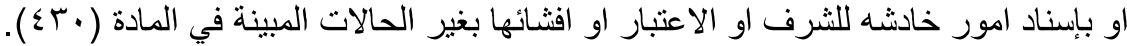

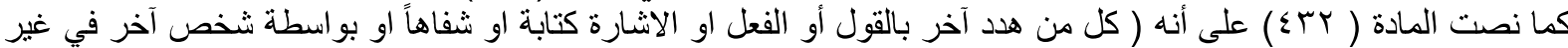

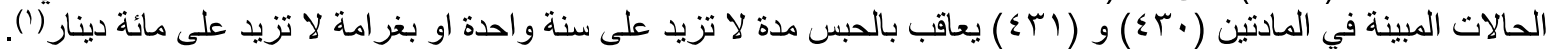

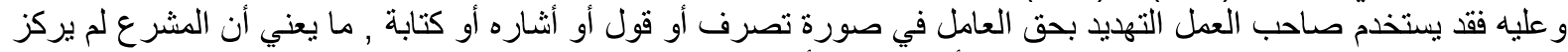

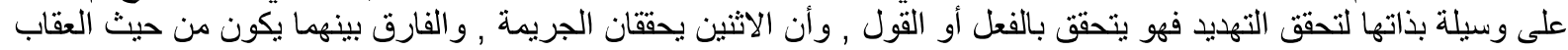

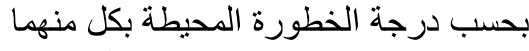

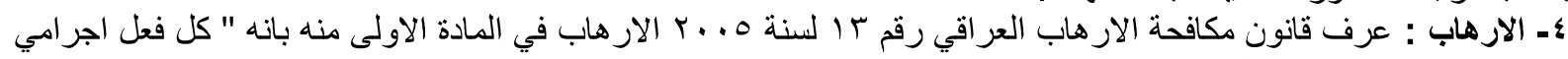

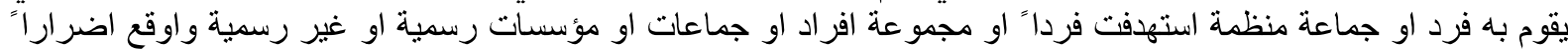

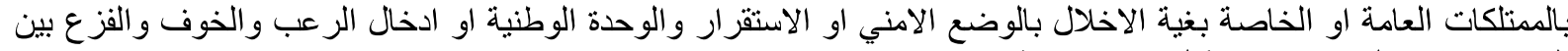

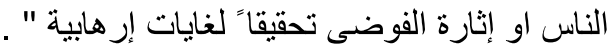

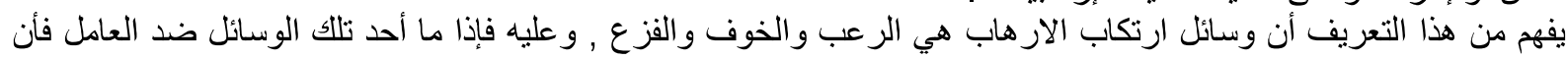

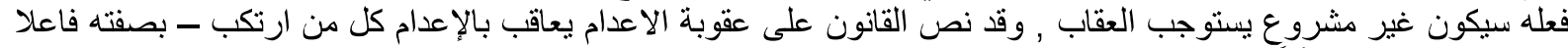

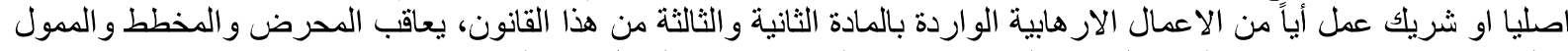

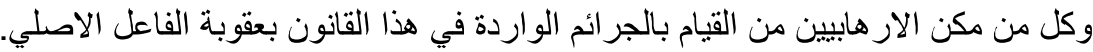

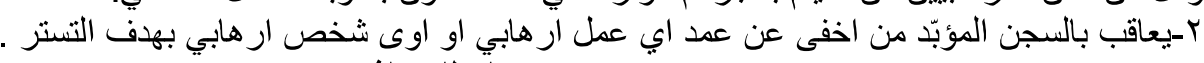
المطلب الثاني

أغراض المعاملة ألسيئة

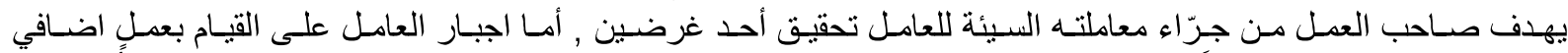

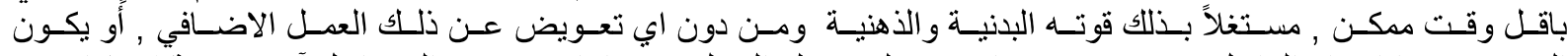

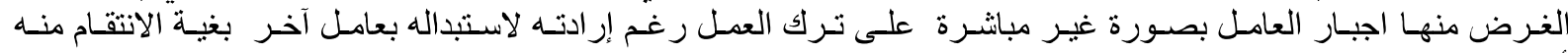

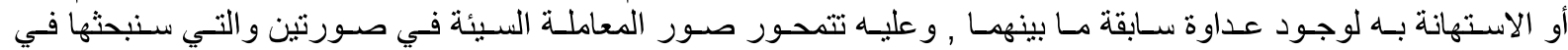

\section{الفرع الاول}

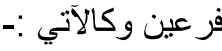

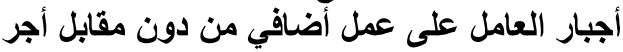

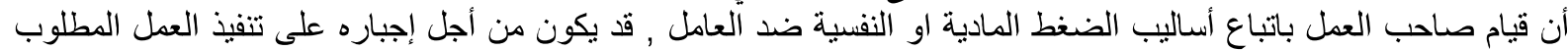

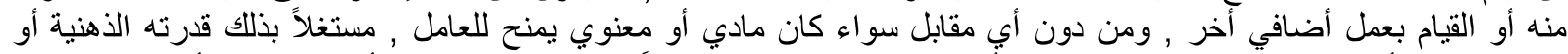

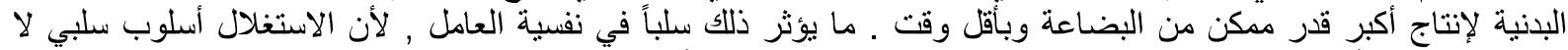

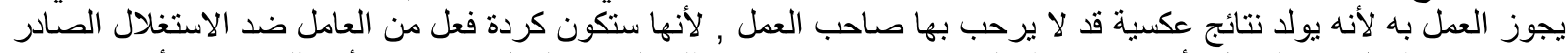

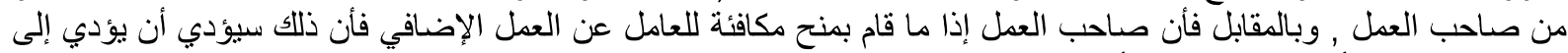

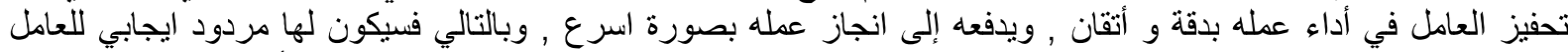

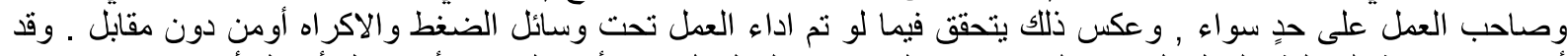

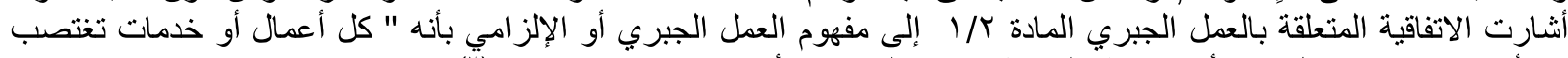

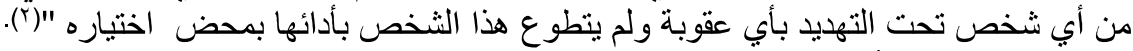

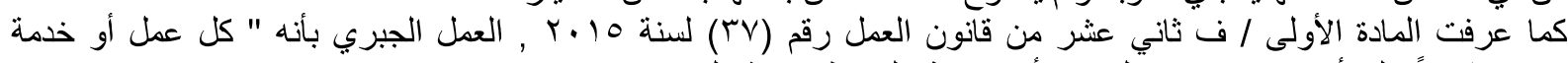

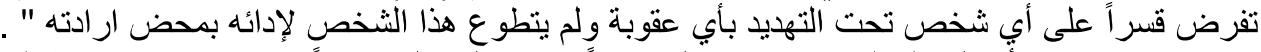

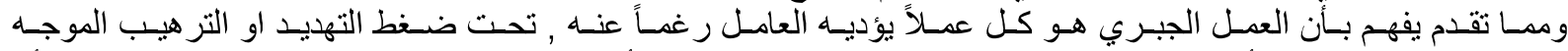

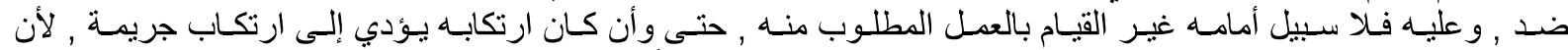

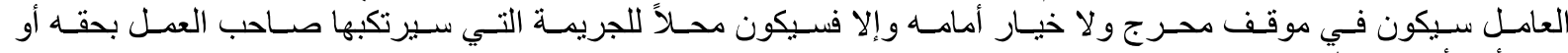
ضده أحد أفراد عائلته .

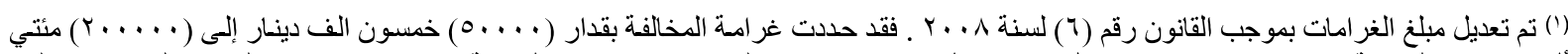

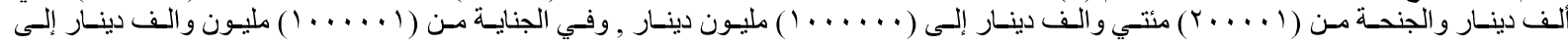

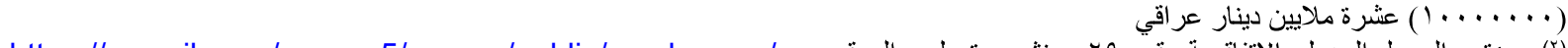

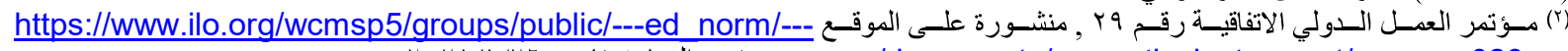

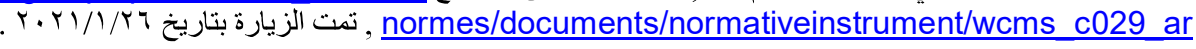




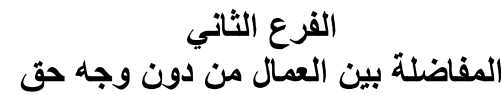

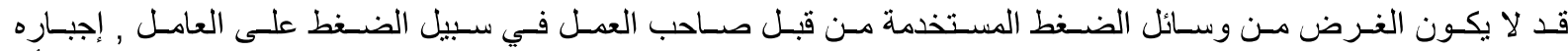

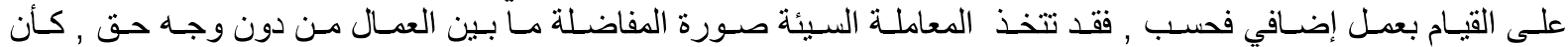

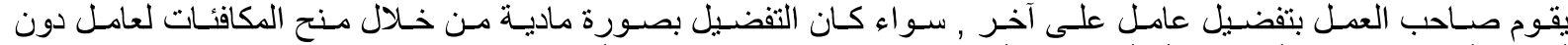

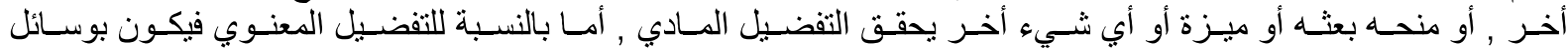

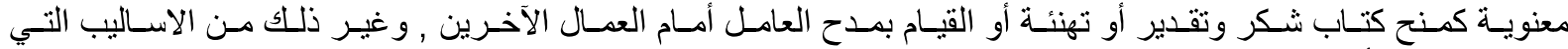

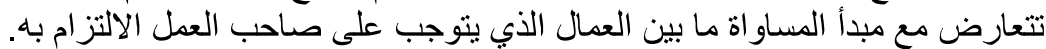

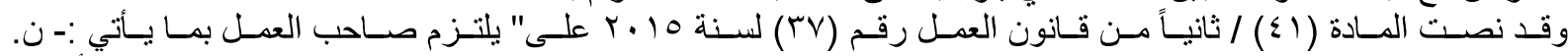

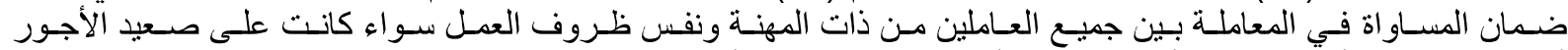

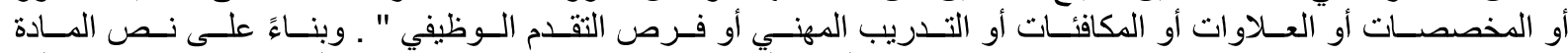

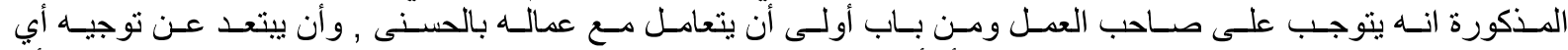

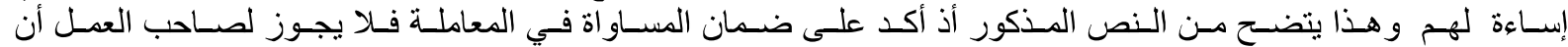

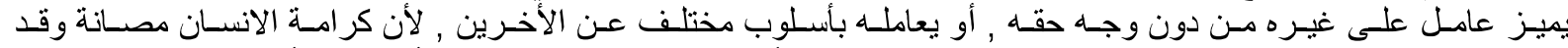

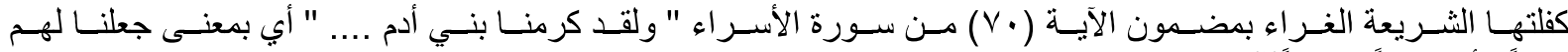

كرماً , أي شرفاً وفضلاًاً (')

\section{مفهوم التكييف الثانوني اللمعاملة السيئة}

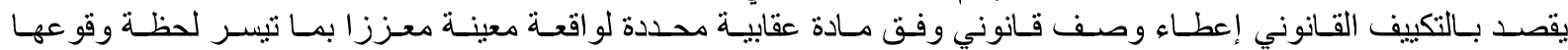
من وقائع(广).

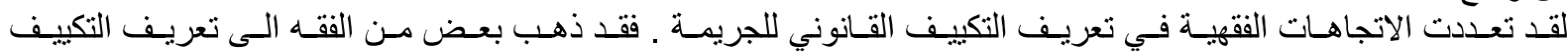

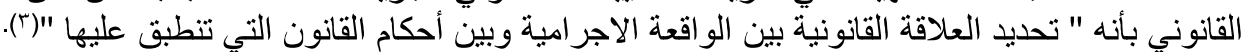

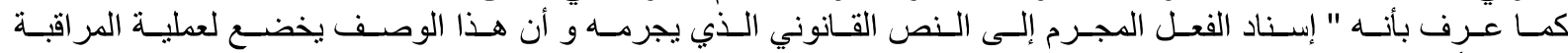

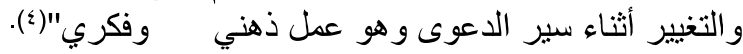

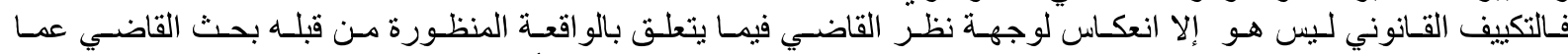

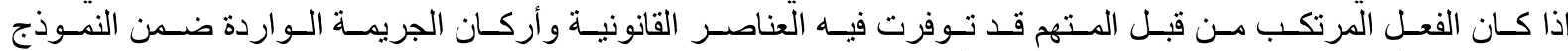

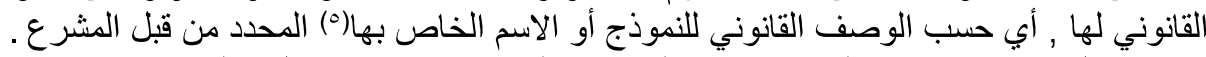

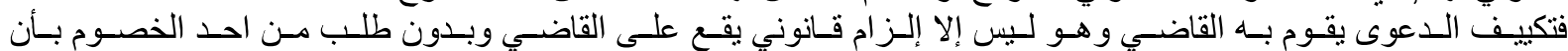

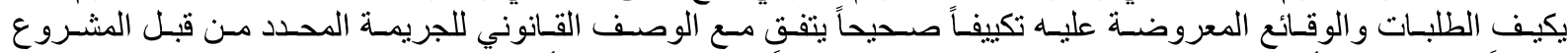

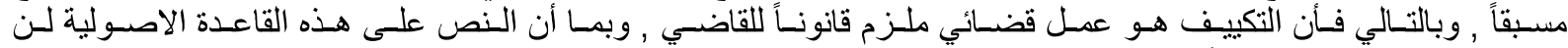

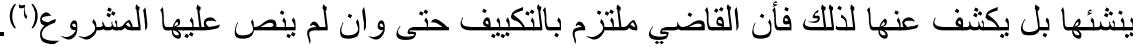

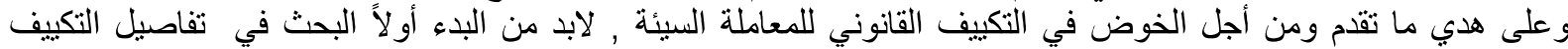

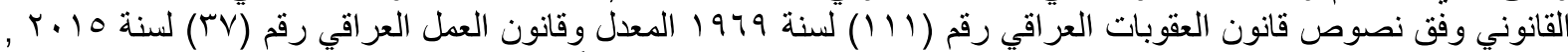

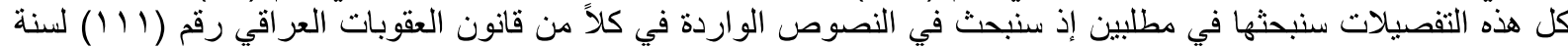

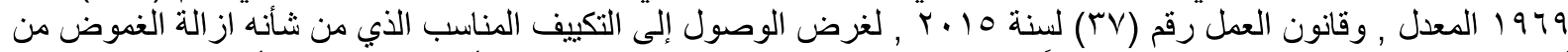

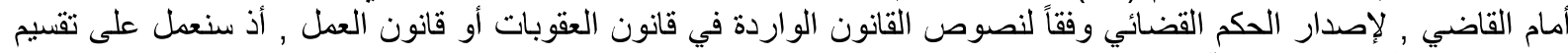

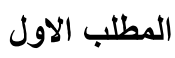
هذا المبحث على فر عين وكالآتي :- الإني

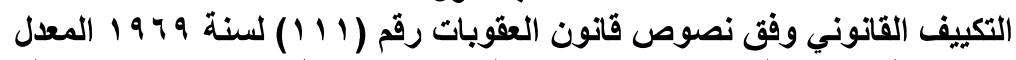

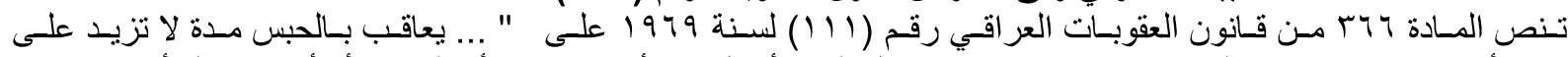

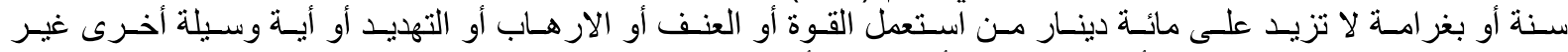

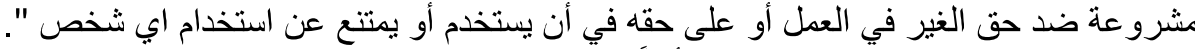

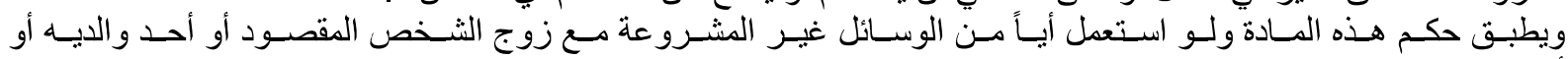
أو لاده.

(') تفسير القرطبي , منشور على الموقع الالكتروني http://quran.ksu.edu.sa/tafseer/qortobi/sura17-aya70.html , تمت زيارة

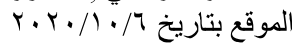

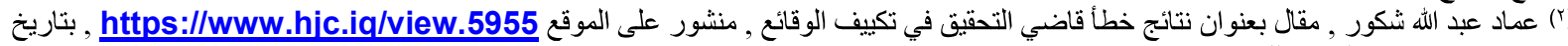

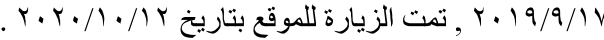

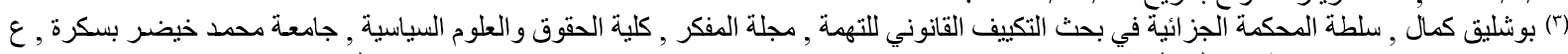

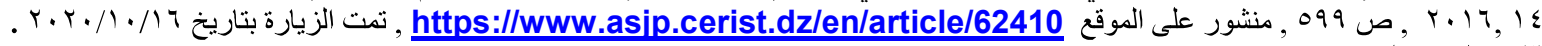

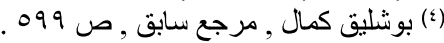

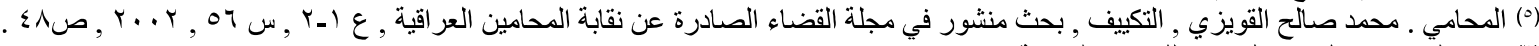

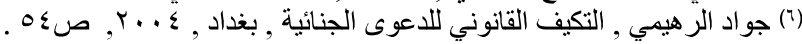




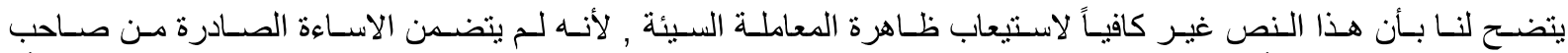

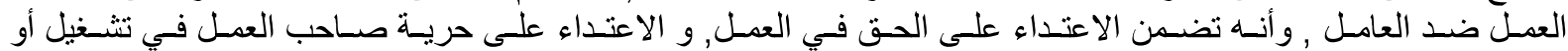

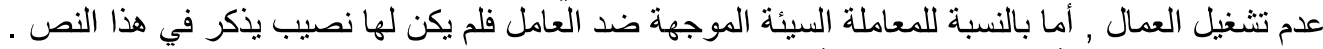

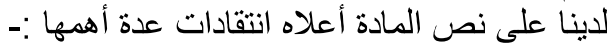

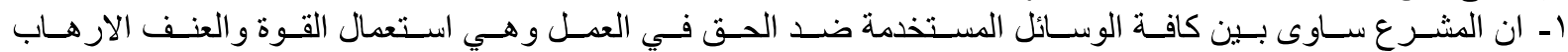

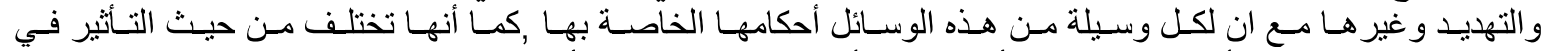

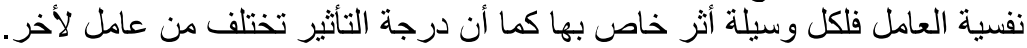

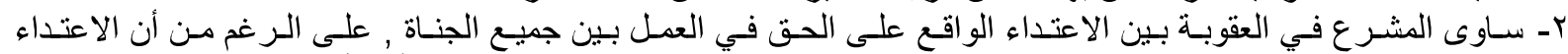

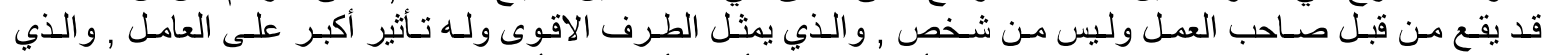

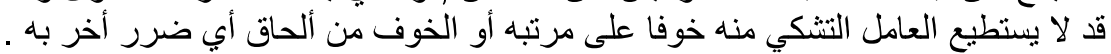

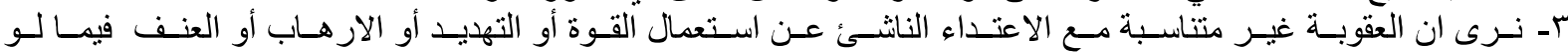

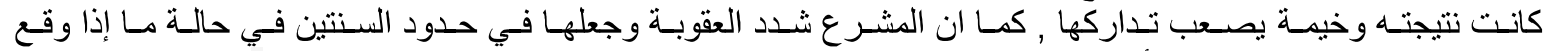

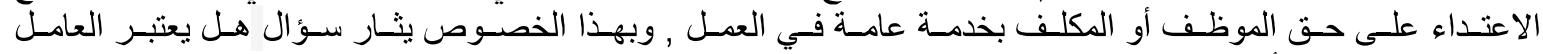

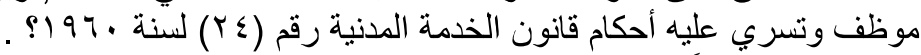

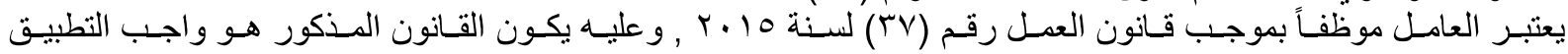

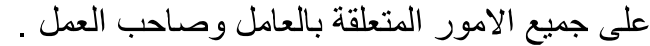

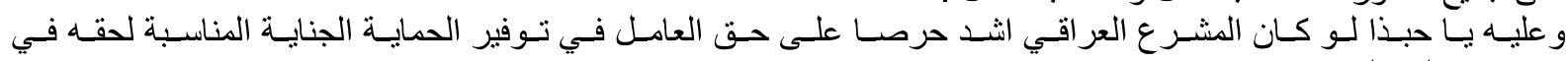

\section{المطلب الثاني

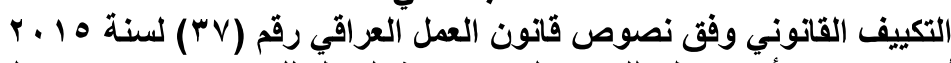

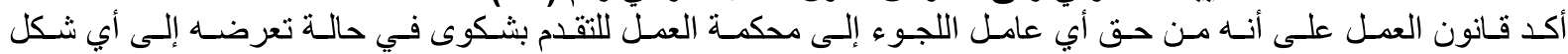

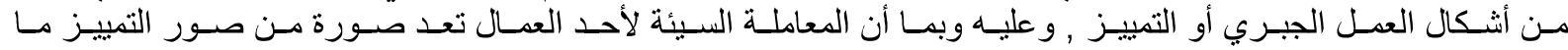

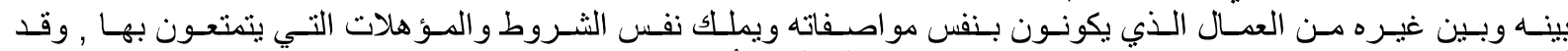

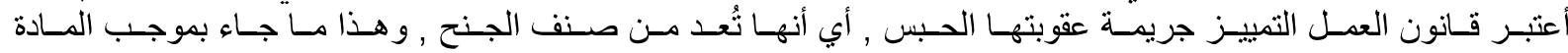

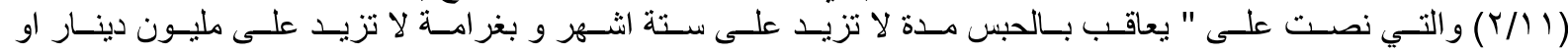

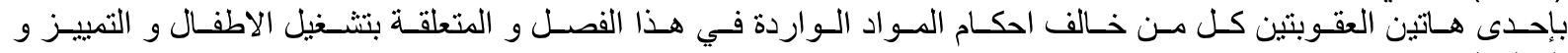

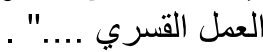

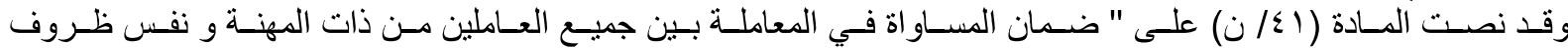

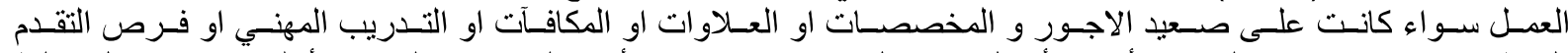

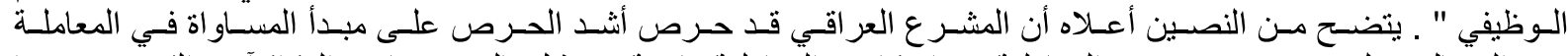

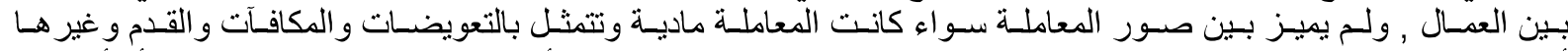

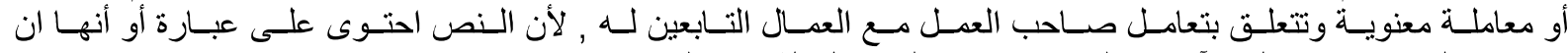

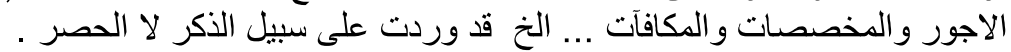

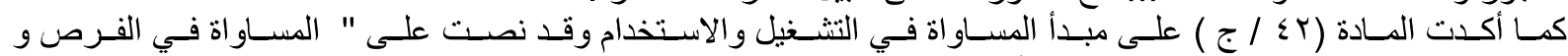

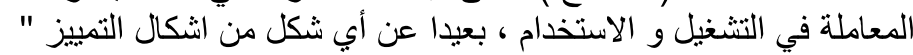

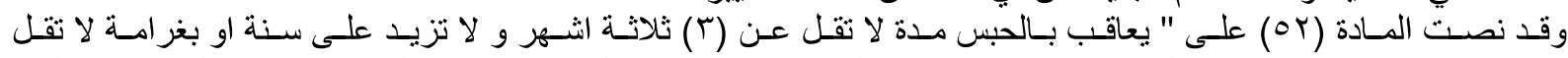

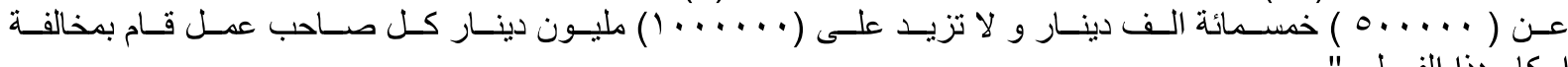

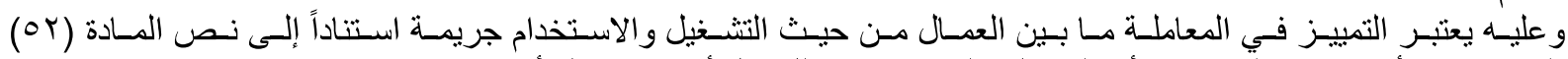

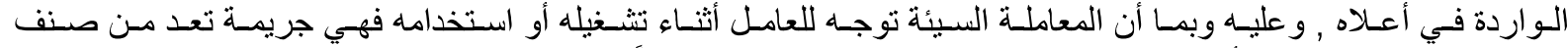

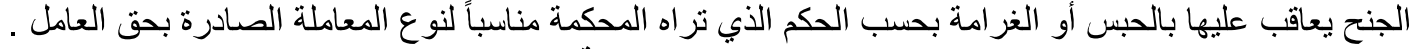
الخاتمة

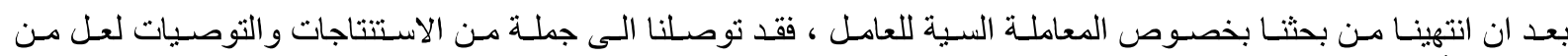

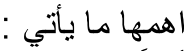

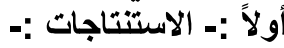

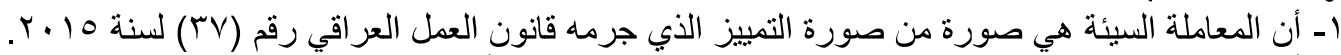

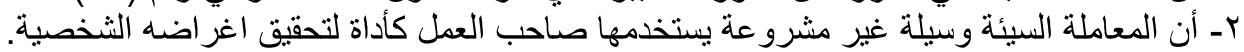

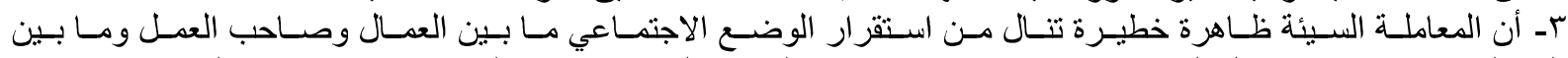

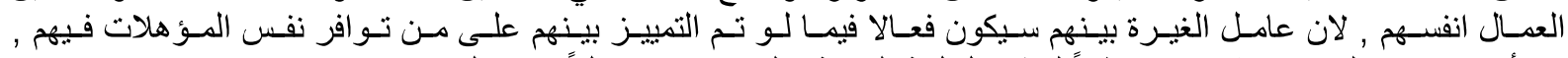

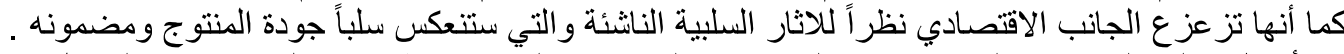

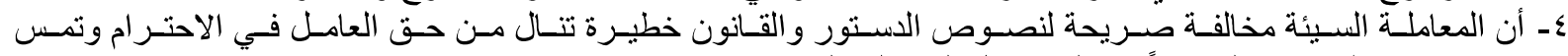

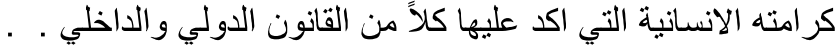


هـ أن نصوص قانون العقوبات غبر كافية لاستيعاب ظاهرة المعاملة السيئة , و لا حتى نصوص قانون العمل .

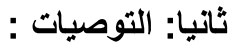

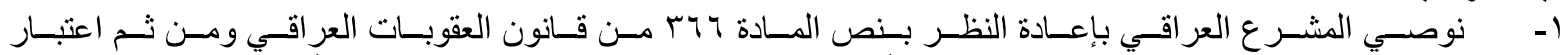

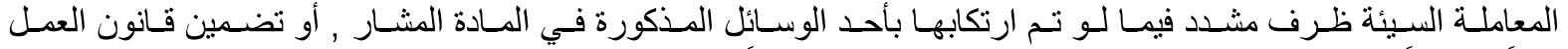

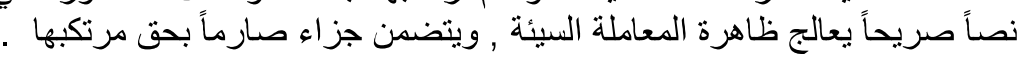

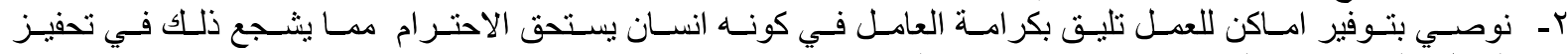

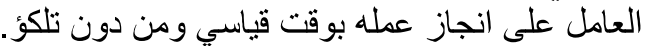

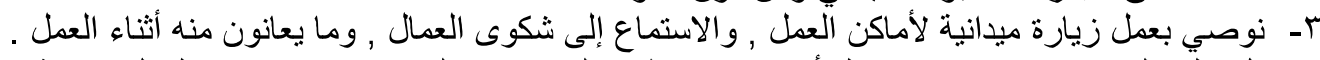

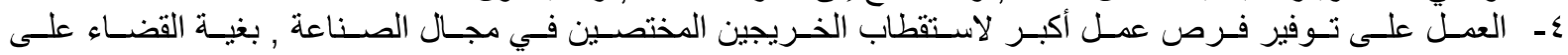

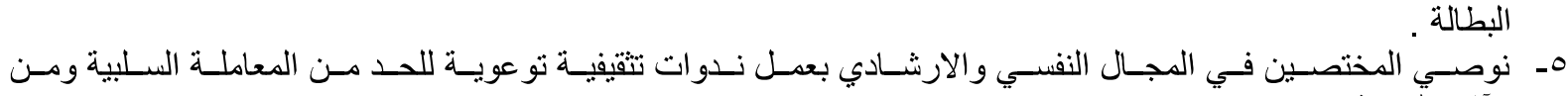

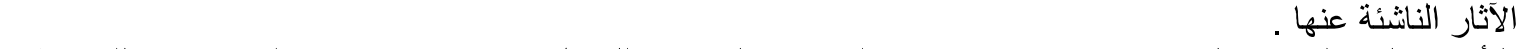

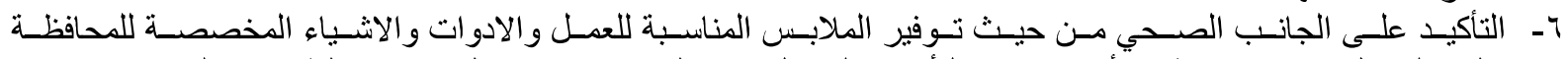

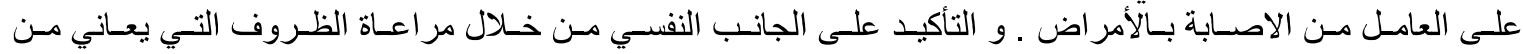

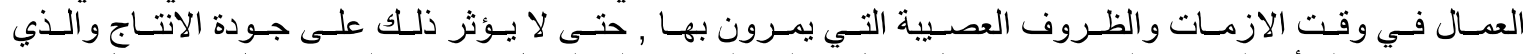

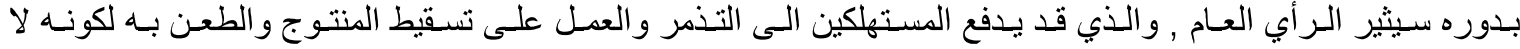

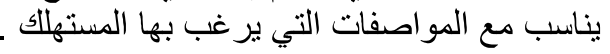

\section{المصادر}

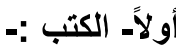

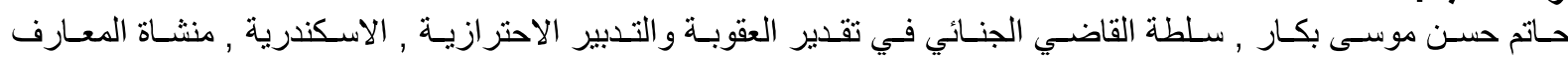

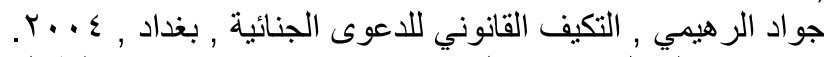

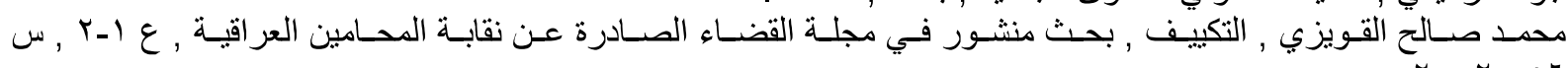

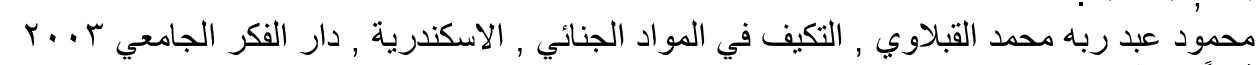

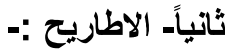

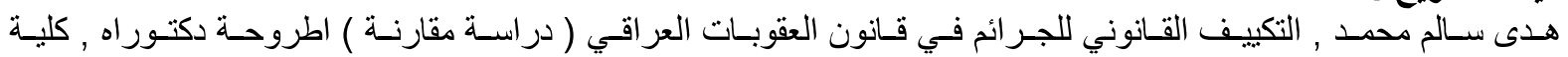

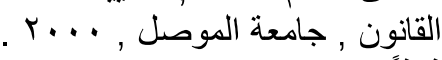

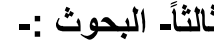

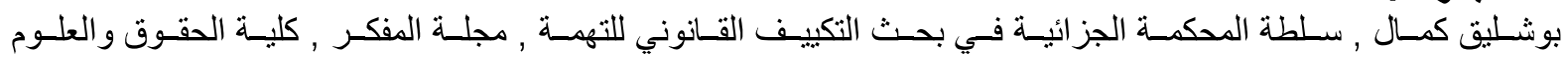

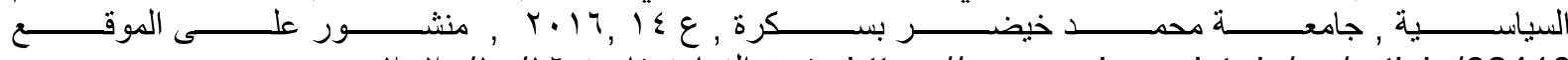

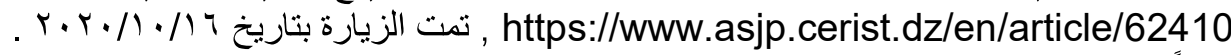

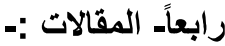

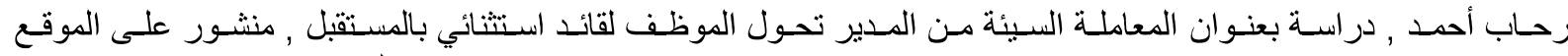
https://al-ain.com/article/bosses-mistreatment-leadership $r \cdot r \mid / T / 1$.

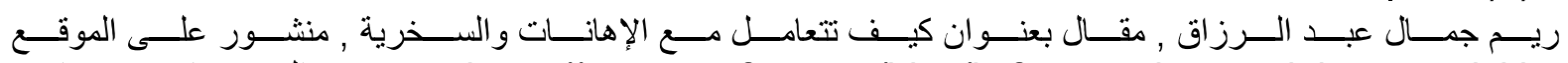
, https://www.acofps.com/blog/kyf-ttaaaml-maa-alehanat-oalskhry $r \cdot r \mid / r / l$.

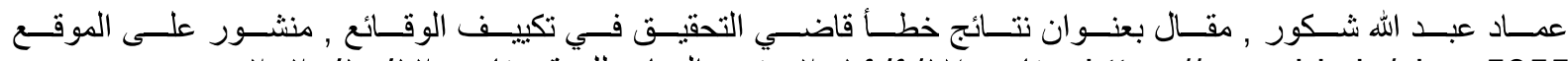

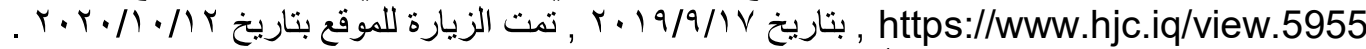

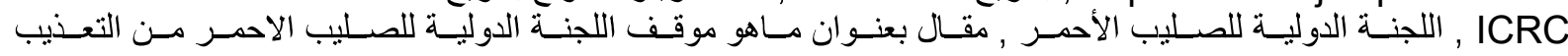

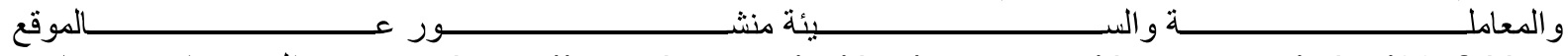
, ittps://www.icrc.org/ar/doc/resources/documents/misc/69vfvj.htm

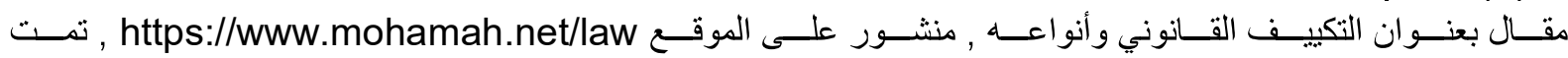

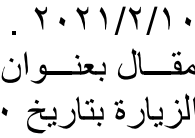

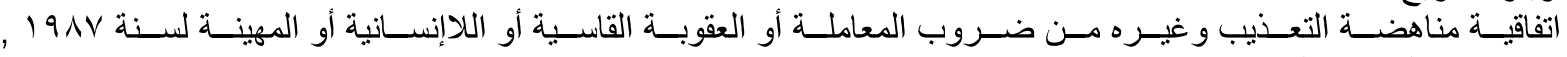

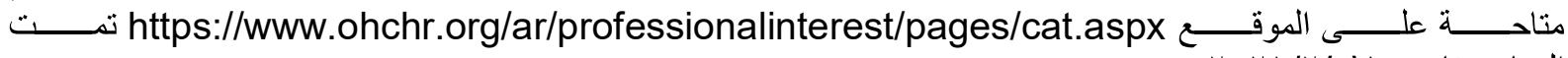

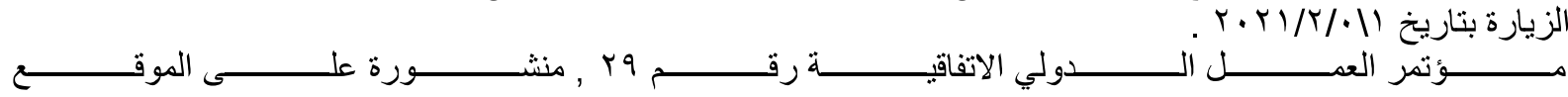
https://www.ilo.org/wcmsp5/groups/public/---ed_norm/--- 


$$
\begin{aligned}
& \text { normes/documents/normativeinstrument/wcms_c029_ar }
\end{aligned}
$$

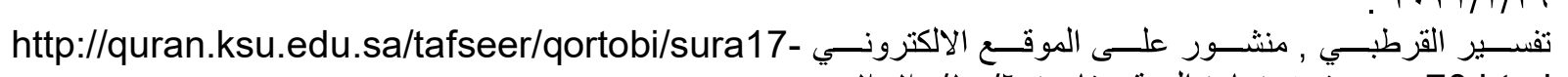

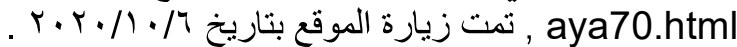

$$
\begin{aligned}
& \text { خامساً. القوانين :- }
\end{aligned}
$$

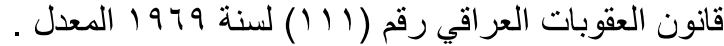

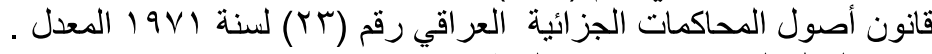

$$
\begin{aligned}
& \text { قانون العمل العراقي رقم (VY) لسنة } 10 \text { •.r. }
\end{aligned}
$$

Abstract

Bad treatment is one of the coercive means that the employer uses against the worker, to force him to perform the work agreed upon under the work contract and for free, or for a small fee that does not interfere with the effort expended by the worker to complete the work assigned to him, the motive for using it may be revenge against the worker because of hostility former, or because of jealousy because the worker possesses qualities or things that distinguish him from the employer, so he treats him badly with the intent to insult him or belittle him, or with the intent to provoke or threaten him, or with the intent of achieving any other goal that has not been agreed upon under the work contract This bad treatment constitutes a severe assault on the worker's right to his safety, his right to privacy, or his freedom, as is the case if the employer forces the worker to work for long hours against his will and without compensation. All of these attacks constitute a violation of the interests that are protected by the penal legislature. It is necessary to search for the appropriate adaptation to the bad treatment, in order to reduce it and its negative effects.

keywords: Bad treatment, worker, work contract, Iraqi law. 